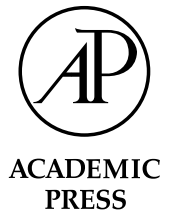

\title{
Differences in the perception and time course of syntactic and semantic violations
}

\author{
Marica De Vincenzi, ${ }^{\mathrm{a}, \mathrm{b}, *}$ Remo Job, ${ }^{\mathrm{c}}$ Rosalia Di Matteo, ${ }^{\mathrm{d}}$ Alessandro Angrilli, ${ }^{\mathrm{e}}$ \\ Barbara Penolazzi, ${ }^{\mathrm{e}}$ Laura Ciccarelli, ${ }^{\mathrm{c}}$ and Francesco Vespignani ${ }^{\mathrm{e}}$ \\ a Dipartimento of Scienze Biomediche, University of Chieti, Chieti, Italy \\ ${ }^{\mathrm{b}}$ Istituto di Scienze e Tecnologie della Cognizione del CNR, Rome, Italy \\ ${ }^{\mathrm{c}}$ Department of Developmental and Social Psychology, University of Padova, Padova, Italy \\ ${ }^{\mathrm{d}}$ Department of Clinical Sciences and Bioimages, University of Chieti, Chieti, Italy \\ ${ }^{\mathrm{e}}$ Department of General Psychology, University of Padova, Padova, Italy
}

Accepted 10 December 2002

\begin{abstract}
A reading time and an ERP experiment conducted in Italian investigated the parser's responses to a syntactic violation (subjectverb number agreement) and to a semantic violation (subject-verb selectional restriction), examining the time course of comprehension processes until sentence end. The reading-time data showed that the syntactic violation was detected earlier than the semantic one and that the two violations differed in the time-course. The ERP data fully supported the reading time data: Syntactic anomalies elicited a left anterior negativity (LAN) and a P600. Semantic anomalies elicited a N400 centred on the parietal sites which started $90 \mathrm{~ms}$ later (latency $430 \mathrm{~ms}$ ) than the LAN. Furthermore, the N400 evoked by the words that followed the target word continued and increased until sentence end. The results are discussed with respect to the hypotheses that the parser constructs distinct syntactic and semantic analyses of a sentence and that this characteristic holds cross-linguistically. The appropriateness of different methodologies to the study of sentence processing is also evaluated.
\end{abstract}

(C) 2003 Elsevier Science (USA). All rights reserved.

Keywords: Syntax; Semantics; Violations; Sentence processing; ERPs; Reading times

\section{Introduction}

One of the basic abilities of native speakers of a language is to recognise what sentences are "acceptable," that is whether they obey the rules of good formation in that language. For example, sentence (1b) violates the number agreement rule between subject and verb:

(1a) The old waiter serves with a vacant look.

(1b) *The old waiter serve with a vacant look

Instead, in sentence (2b) the subject-verb relation is not semantically plausible:

(2a) The tired tailoress irons without paying attention.

(2b) *The tired tailoress growls without paying attention.

\footnotetext{
${ }^{*}$ Corresponding author.

E-mail address: mdevince@tiscali.it (M. De Vincenzi).
}

The ability to recognise acceptable sentences has been used as a tool to investigate the functional architecture of the human sentence processor since the detection of these violations immediately provokes alterations in the normal comprehension process. For example, in reading, the detection of these violations generally shows up in a disruption of reading times as soon as the violation is perceived (Freedman \& Forster, 1985). From a psycholinguistic point of view, the first issue of interest is what is the temporal relation between the time in which number agreement violation is detected and the time in which semantic violation is detected. In fact, the temporal comparison can shed light on the processing dynamics of human sentence parsing (Boland, 1997; Braze, Shankweiler, Weijia Ni, \& Palumbo, 2002; Fodor, Ni, Crain, \& Shankweiler, 1996; McElree \& Griffith, 1995; Ni, Fodor, Grain, \& Shankweiler, 1998). 
The second interesting issue is the time course of the parser's response to syntactic and semantic violations. In fact, a differential response to the two kinds of violations, such as a differential delay in interpretative commitment, is a manifestation of a principled distinction between syntactic and semantic processing procedures within the human language processing mechanism. This comparison can therefore, give us important information about the architecture of human language.

In the last decade, several pieces of experimental evidence regarding this issue have been collected using behavioural measures. McElree and Griffith (1995) used a response-signal version of an acceptability judgment task and found a delay in detecting semantic/pragmatic anomalies with respect to syntactic anomalies. Boland (1997) with a cross-modal naming task also found such a delay. These data are compatible with the view that syntactic and semantic processes are independent and that syntactic processing precedes semantic computation. However, Fodor et al. (1996) have pointed out potential problems for this interpretation of the data. In their study they compared different methods: a dual-task paradigm with compressed speech input and lexical decision on temporally contiguous visually presented strings, and a "stop-making-sense" task, again with a compressed input. The stimuli were unambiguous violated sentences. The syntactic violation was always in the sequence "modal verb-ing form" (as in "the cats won't eating..") while the pragmatic violation was in the pairing between agent and action (as in "the cats won't bake.."). In the lexical decision task, the influences of syntactic and pragmatic violations did not show significant differences. ${ }^{1}$ In the "stop-making-sense" task slower reaction times to the pragmatic violation were detected (confirming the results reported by McElree \& Griffith, 1995). However, according to Fodor et al. (1996) the comparison between the lexical decision task, in which violations were not the focus of the task (need not be considered in performing the task) and the "stopmaking-sense" task, where violation recognition is instead the focus of the task, shows a limit of the judgement task. In fact, the slower reactions to the pragmatic violations can be attributed to a delay in the overt judgement, and not necessarily to a delay in the detection of the anomaly. Therefore, since the characteristics of the task itself can introduce differences in the results even with the same experimental material, the nature of the task for investigating processing events is crucial. The conclusion of Fodor et al. (1996) is that, when

\footnotetext{
${ }^{1}$ Fodor et al. (1996) found that only pragmatic anomalies were sensitive to post-sentential comprehension tasks. Syntactic anomalies, instead, produced a constant effect across tasks. According to the authors, this is a sign that syntactic processing is mandatory, and mandatoriness is a feature of a module at work, in the sense of J.A. Fodor (1983).
}

studying linguistic processing, it is important to adopt indirect measures.

Braze et al. (2002) and $\mathrm{Ni}$ et al. (1998) recorded eye movements using the same material used by Fodor et al. (1996). Both studies showed a distinct pattern for the time-course of the violations: Syntactic anomalies (eating) generated more regressions than controls on the verb and on the following word, returning to baseline on the rest of the sentence. Instead, semantic violations (bake) exhibited an increase in the number of regressions that continues until sentence end. This pattern of results indicates that the parser's processing routines for syntax and semantics are distinct, in that syntactic information is locally integrated and resolved, while semantic information integration continues until the end of the sentence. Focusing on the initial detection of the violation, $\mathrm{Ni}$ et al. (1998) analysed a twoword segment (the verb plus a following word), while Braze et al. (2002) also analysed the single-word data. This latter analysis shows clearly that for the syntactic violation regressions initiate immediately on the verb, while for the semantic violation the regressions (and fixation times) increase only on the word following the verb.

The conclusion from these behavioural studies is therefore, that while there is little consensus about the relative timing of the detection of syntactic and pragmatic anomalies, there are clear indications for a dissociation in the course of actions that the two violations elicit in the sentence.

These issues have also been investigated employing the recording of Event Related Potentials (ERPs) elicited during language comprehension. ERPs are on-line continues measures of the brain electrical activity that occurs during language comprehension. ERP measures are multidimensional: They vary in polarity, timing, morphology, and scalp distribution. Therefore, compared to other behavioural methods such as reading time, they can provide evidence whether certain processes vary on one or more dimensions such as timing and/or polarity. Furthermore, ERPs provide evidence of the cortical processes involved in parsing without adding interfering tasks.

Concerning the issue of the distinction between semantic and syntactic processes, ERP research has in fact shown distinct responses for the two linguistic processes. Semantically inappropriate words show a negative component, generally distributed all over but more intense in the posterior areas, peaking at about $400 \mathrm{~ms}$ after stimulus onset, called the N400 effect (for a review, see Kutas \& Van Petten, 1994 or Osterhout \& Holcomb, 1995). This effect is quite well assessed and has been found in different languages (such as English, Dutch, German) and in different modalities (visual as well as auditory Hagoort \& Brown, 2000a; and sign language, Neville, Mills, \& Lawson, 1992). 
Things are less uniform when turning to the ERP correlate of syntactic processing, because a variety of different syntactic structures and corresponding violations have also been tested. To summarise, we can say that with respect to syntactic processing two ERP components have been identified: An early left anterior negativity (LAN) and a late centro-parietal positivity. Syntactic anomalies elicit a negative polarity between 200 and $500 \mathrm{~ms}$ from stimulus onset: This negativity are usually largest over left anterior sites and is therefore called Left Anterior Negativity or LAN. An early LAN (also called ELAN) around $250 \mathrm{~ms}$ has been found in response to phrase structure violations (Friederici, Pfeifer, \& Hahne, 1993; Neville, Nicol, Barss, Forster, \& Garrett, 1991). A LAN between 300 and $500 \mathrm{~ms}$ has been reported in correlation with subject-verb number agreement violations (Coulson, King, \& Kutas, 1998; Friederici \& Mecklinger, 1996; Hagoort \& Brown, 2000b; Kutas \& Hillyard, 1983; Osterhout \& Mobley, 1995) and verb's sub-categorization violation (Osterhout \& Holcomb, 1992; Rosier, Putz, Friederici, \& Hahne, 1993).

The second component reported in correlation with syntactic processes is a large-amplitude, centro-parietal positivity generally labelled P600 that starts around $500 \mathrm{~ms}$ after presentation of the syntactically critical word and persists for several hundred milliseconds. It is elicited by anomalies involving phrase structure, verb tense, subject-verb number agreement, case violations, and also by constituent movement and garden-path sentences (Ainsworth-Darnell, Shulman, \& Boland, 1998; Coulson et al., 1998; Friederici \& Mecklinger, 1996; Gunter, Stowe, \& Mulder, 1997; Hagoort \& Brown, 2000b; Hagoort, Brown, \& Groothusen, 1993; Kaan, Harris, Gibson, \& Holcomb, 2000; McKinnon \& Osterhout, 1996; Neville et al., 1991; Osterhout \& Holcomb, 1992, 1993; Osterhout \& Mobley, 1995; Osterhout \& Nicol, 1999).

To summarise, the ERP data show a distinct response for syntactic and semantic processes, which support models that include such a distinction. Within syntactic processing, they support a two-stage model of syntactic processing, where there is an initial stage of violation detection (ELAN/LAN) and a later stage of syntactic repair (the P600) (see Friederici, 2002, for a review).

The present research is aimed at establishing the relative timing of the detection of syntactic and pragmatic anomalies in sentences. Among the many possible syntactic and semantic violations, we chose to study violations that were expressed in the subject-verb relation, so that the word class of the critical word is identical across anomaly type (cf. Osterhout \& Nicol, 1999, for a discussion of the confounding of anomaly type and word class of the violations). In particular, the syntactic violation is a subject-verb number agreement mismatch while the semantic violation is a subject-verb selectional restriction mismatch.
A first important aspect of the research is the close comparison between behavioural and ERP data, in order to link neural correlates and behavioural results. To this end, we report two experiments. The first one is a reading time study, to obtain data on when the violations are first detected and where the processing load of the violation in reading shows up. The second one is an ERP study using the same set of sentences to obtain electrophysiological measures on the same aspects. The comparison allows us to detect analogies and differences between qualitatively different measures and enables us to integrate the findings on the topic in a more comprehensive picture.

A second important aspect of the research is that the consequences of the violations are analysed up to the end of the sentence. In reading time the only available data on the whole sentence are those on eye-movements from Braze et al. (2002) and Ni et al. (1998). Regarding ERP studies, most of them have so far considered as a critical region only the target word and occasionally also the last word of the sentence. Further, in several studies, the final word coincides with the critical word (see, for example, Gunter et al., 1997; Penke et al., 1997; Rosier et al., 1993). This introduces the possibility that the response to the anomaly is at least partially confounded with end-ofsentence wrap-up, decision and response processes, as pointed out by Osterhout and Nicol (1999). Further, we should note that when the critical word is placed in sentence final position it is impossible to examine how the critical word affects sentence processing because there is no remaining part of the sentence to be analysed. Therefore, given the pattern showed by Braze et al. (2002) and $\mathrm{Ni}$ et al. (1998) we thought it is crucial to have sentences with violations in internal position and to record ERPs for the entire sentence. This would allow us not only to compare the ERP data directly with the eye-movement data, but also to be able to trace the neural correlates of the time course of different linguistic violations.

A third important aspect of the present research is that it is conducted in Italian. This point is relevant regarding models of sentence comprehension. In fact, different theories of sentence comprehension have different crosslinguistic implications. Modular theories (Fodor, 1983; Forster, 1979; Frazier \& Fodor, 1978) claim that the parser constructs distinct syntactic and semantic analyses of a sentence. A further implication is that this architecture is innate and consequently it should be universal, i.e., the separability of the processes and the way they interact should hold across different languages. In contrast, for Interactive theories (Bates \& MacWhinney, 1987; MacDonald, Pearlmutter, \& Seidenberg, 1994; MacWhinney \& Bates, 1989; Marslen-Wilson, 1975; Taraban \& McClelland, 1988), syntactic and semantic constraints interact directly and simultaneously and, furthermore, their relative weight depends on probabilistic constraints that may well vary across languages. 
One way of contrasting these views is to examine the processing of the subject-verb agreement relationship. In English subject-verb agreement violations elicit a distinct pattern of a LAN followed by a positive shift (P600) for syntactic violations and a negative shift (N400) for semantic violations (Osterhout \& Mobley, 1995). We studied the same subject-verb relations in Italian. However, Italian has more freedom of word order than English and in this respect different parsing models make different predictions regarding the effects of the violations. According to the Competition model (Bates \& MacWhinney, 1987; MacWhinney \& Bates, 1989) the detection of a subject-verb agreement violation should be influenced by the fact that the conditional probability of being a subject for a sentence initial noun is much stronger in English than in Italian, and this detection should be more influenced by semantic factors (such as animacy) in Italian than in English. Consequently, we should expect that the behavioural and neuro-physiological responses to syntactic and semantic violations are less distinct in Italian than in English. Instead, for the (putatively) universal parser, the computation of a subject-verb agreement relation should be done in the same manner in either language (i.e., the first noun should be immediately computed as subject) and therefore the processing effects should be similar across languages (De Vincenzi, 1991).

Finally, an important methodological point of this research is that in both experiments we never asked any linguistic judgement of the participants. This because the characteristics of the judgement task itself can introduce differences in the results, as carefully described by Fodor et al. (1996). Therefore, we adopted a more indirect measure to keep high participants' attention, which consisted in a few comprehension questions on general sentence content, and never related to the violation.

\section{Experiment 1: A Reading time study}

\subsection{Method}

\subsubsection{Participants}

Thirty undergraduates of the University of Chieti participated in the experiment (16 females, 14 males; age-range: $18-25$ years). All were native Italian speakers.

\subsubsection{Materials}

A total of 120 pairs of sentences were constructed, as exemplified in sentences 1-2 in Table 1 . The entire set of experimental materials is listed in the Appendix. Half of the sentences were well-formed; half contained either a syntactic or a semantic violation.

In the syntactic violation set, one version of each pair of sentences had a violation of number agreement between the subject and the verb.
Table 1

Syntactic violations

Il cameriere anziano serve/servono con espressione distratta.

The old waiter serves/serve with a vacant look.

Semantic violations

Il nuovo capotreno fischia/germoglia alla partenza della locomotiva.

The new guard whistles/sprouts at-the departure of-the locomotive.

Examples of experimental sentences. The critical words (the verb, always in fourth position) are underlined and the two alternatives are separated by slashes. The first verb is the correct version, the second verb is the violating version.

In the semantic violation set, one version of the pair had a violation of the semantic/pragmatic agreement between the subject and the verb. In this case, the nonanomalous and semantically anomalous critical words (the verb) were matched in frequency (nonanomalous: mean $=177.67$; anomalous: mean $=178.30, F[1,118]=$ $0.00, p=.99, M S E=12.03$; Istituto di Linguistica Computazionale del CNR, 1989) and length in letters (nonanomalous: mean $=6.33$, anomalous: mean $=6.42$, $F[1,118]=0.11, p=.74,(M S E=1.90)$.

In addition, the following criteria apply to all the materials: The critical word (i.e., the one containing the violation) was always a verb in the present tense, either intransitive or transitive without a direct object. The critical word was always in fourth position with three words preceding it and either three or four words following it. The verb was four to nine letters long so that it could be read in a single eye fixation. No word in the sentences was longer than 12 letters.

The grammatical number (singular or plural) of the sentence subject was balanced: Half of the sentences had a singular subject, half had a plural subject. In addition, the animacy of the subject was balanced: One third of the sentences had human subject, one third had nonhuman animate subject, and one third had inanimate subject.

The above materials were counterbalanced across two stimulus lists such that each list contained only one version of each experimental pair.

In addition to the experimental sentences, a set of sixty pairs of filler sentences was constructed with different syntactic structures and containing no violations. Hence, across all the materials, each participant saw 180 sentences: 30 contained a syntactic violation, 30 contained a semantic violation, and 120 were well formed sentences.

\subsection{Procedure}

Participants seated in front of a computer screen. Sentences appeared on a PC monitor one word at the time, at the centre of the screen. The task was self-paced 
reading: Participants controlled the presentation rate of each word by pressing a "go" button. They were told that they would have to read a series of sentences, some of which were strange or incorrect. They were asked to read as rapidly as they could while maintaining good comprehension. To insure that participants paid attention to the sentences, every ten sentences (on average) there was a comprehension question, never related to the linguistic violations (e.g.: Is the waiter alert?). The participants responded to the questions pressing a YES or NO button.

To familiarise the participants with the task, a practice session was run. This consisted of ten sentences resembling the experimental and filler items in the experiment.

\subsection{Predictions}

Regarding the time of the detection of the anomaly, modular theories predict an earlier recognition of the syntactic (number agreement) violation than of the semantic one. This should be indexed by a quick increase in reading time on the violating word, due to the fact that the syntactic parser immediately and independently computes a syntactic structure that feeds the semantic processor (Frazier \& Rayner, 1982). Instead, interactive theories predict a similar timing for the detection of both violations, given that syntactic and semantic constraints work directly and simultaneously. Regarding the consequences of the violations, we expect that the syntactic violations will only produce a temporary disturbance, in that the ease of the diagnosis should produce a quick repair (cf. Fodor et al., 1996). Instead, the consequences of the semantic violations should extend for a longer time, given that the reader can keep looking for a plausible resolution of the pragmatic inconsistency. These predictions hold particularly well for modular models that make a principled distinction between syntactic and semantic representations and processing. Interactive theories, instead, do not make a principled distinction between these types of information, and on the contrary they emphasise common underlying processes and representations (cf. MacDonald et al., 1994). In this respect these latter models have more difficulties in predicting qualitatively different responses, unless some stipulation is added to the models.

\subsection{Results}

Participants gave the correct response to $90.42 \%$ of the comprehension questions, indicating that they attended carefully to the reading task.

The data on reading times are presented in Fig. 1 (syntactic violations) and Fig. 2 (semantic violations). The mean reading times were computed for each word after eliminating times (less than $1 \%$ ) that were longer than $2000 \mathrm{~ms}$ or shorter than $100 \mathrm{~ms}$. Separate Analyses of Variance (ANOVA) were conducted for the syntactic and semantic condition with reading times as dependent variable and both subjects (Fl) and items (F2) as random factors.

For the syntactic condition Grammaticality of sentences was the within factor with two levels (grammatically correct vs. incorrect sentences) and mean reading times for correct and incorrect sentences were computed separately for each word (see Fig. 1).

On the three words preceding the critical one there were no reading time differences between the grammat-

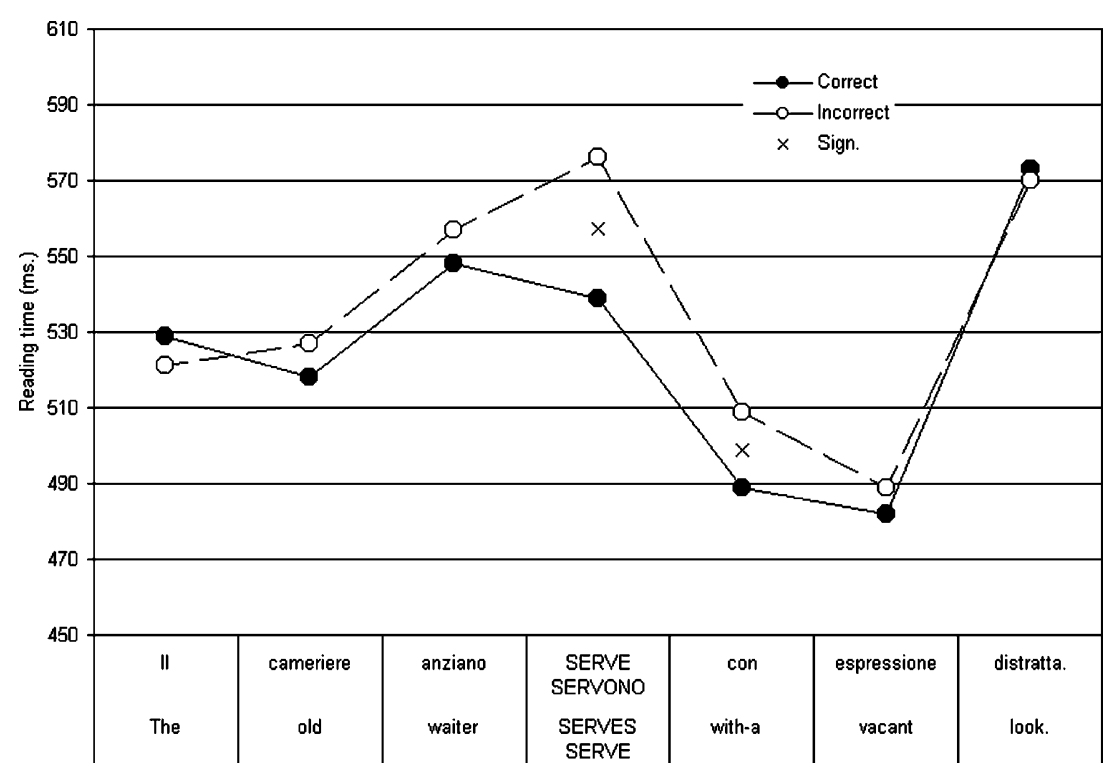

Fig. 1. Average Reading Times (in ms) for the Syntactic violation condition sentences (dashed line) relative to control (solid line). 


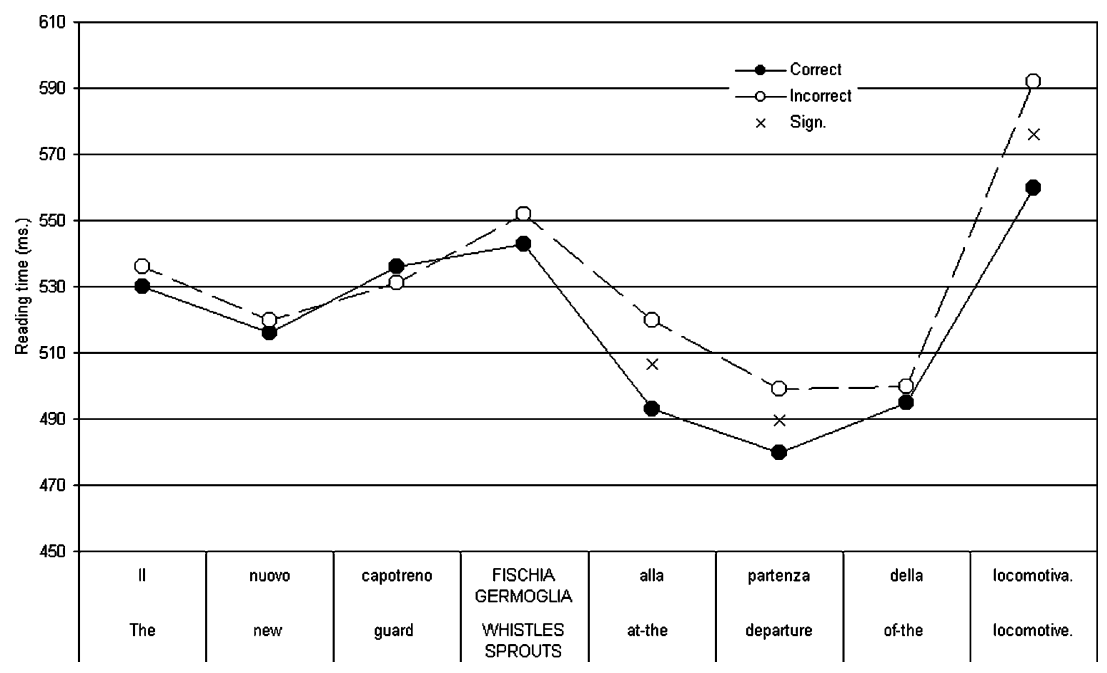

Fig. 2. Average Reading Times (in ms) for the Semantic violation condition sentences (dashed line) relative to control (solid line).

ical and ungrammatical sentences. Reading times of the critical word (the fourth one) in the ungrammatical condition were significantly longer than in the grammatical condition $(F 1[1,29]=11.13, p<.002,(M S E=$ 1784 and $F 2[1,57]=7.30, p<.009,(M S E=5311)$. A significant effect of Grammaticality was also present for the word following the critical word $(F 1[1,29]=5.43$, $p<.027,(M S E=1117$ and $F 2[1,57]=8.50, p<.005$, $(M S E=1435)$. No effects were found on the subsequent words (sixth word and final word).

For the semantic condition, semantically acceptable and semantically unacceptable represented the two levels of the within factor of semantic anomaly of sentences. Reading times for correct and incorrect sentences were computed separately for each word (see Fig. 2).

On the three words preceding the critical word there were no reading time differences between the correct and incorrect sentences. Reading times on the critical word also did not reveal any significant difference. A significant effect of semantic anomaly was present on the two words following the critical word $(F 1[1,29]=9.84$, $p<.004,(M S E=1125$ and $F 2[1,57]=8.76, p<.004$, $(M S E=2483$ for the fifth word position; $F 1[1,29]=$ $7.89, p<.009,(M S E=667$ and $F 2[1,57]=5.19, p<$ $.026,(M S E=1928$ for the sixth word position). No effects were found in the subsequent word position (seventh word). On the final word there was again a significant effect of semantic anomaly $(F 1[1,29]=12.14$, $p<.002,(M S E=1246$ and $F 2[1,57]=8.07, p<.006$, $(M S E=3321)$.

\subsection{Discussion}

The results show that the syntactic anomaly is immediately detected and quickly repaired. It is recognised on the critical word and the perturbance continues only until the next word. Instead for the semantic violation, the detection happens later and lasts longer, until the end of the sentence.

These two combined results support the idea that syntactic information is detected earlier than semantic information and that the two types of violation have different time courses, precisely in the same manner as shown in English by Braze et al. (2002), Fodor et al. (1996), and $\mathrm{Ni}$ et al. (1998). Namely the syntactic violation is apparently easily resolved (the choice is to decide if either the number marking of the subject or of the verb is the wrong one). Instead for the semantic violation things are more complicated: There can be always some alternative semantic interpretation of the utterance, and the reader can keep continuing reading looking for an incoming following context that fixes the incongruency.

We should point out that our results not only confirm a distinct pattern of responses for the two violations, but they show also a faster perception of the syntactic violations, as found in English by Boland (1997) and McElree and Griffith (1995). The fast action of the syntactic processor is a signature of its modular status and the replication of this finding across structurally different languages is evidence in support of the universality of the architecture of the language processor.

\section{Experiment 2: The ERP study}

The ERP experiment used exactly the same material of the reading time study. However, unlike the reading time task, we can obtain a dependent measure, the ERP, without asking the reader to take any specific action. In an ERP study participants, in contrast to the reading time study, do not have to decide to press a button in order to proceed in reading. The ERP methodology registers the cerebral activation during language 
comprehension, not mediated by behavioural processes. Instead, the self-paced reading task could reflect not only perception processes, but also decision processes, even though we avoided explicit judgement or anomaly detection.

Therefore the first reason to run the ERP study was to have a more direct measure of the timing of the anomaly detection. In fact, to study phenomena with such small timing resolution, data from different methodologies are certainly welcome. In particular, the hypotheses relative to the temporal sequence of the processes would be strengthened by agreement between behavioural and electrophysiological results.

The second reason to run the ERP experiment was to examine the scalp electrical activity thorough the whole sentence. The comparable ERP studies on subject verb-agreement violations have usually examined only the critical word and the final word. Instead, our reading time study and the eye-movement experiments of Ni et al. (1998) and Braze et al. (2002) have examined the temporal course until sentence end and have shown differences between syntactic and semantic violations. Therefore, we think that examining the ERP wave on the entire sentence and comparing it to the results of the behavioural study should supply further details on the time course of the comprehension processes.

\subsection{Method}

\subsubsection{Participants}

Twenty-five undergraduates from the University of Padova participated in the experiment (12 males, 13 females; age range: 18-29 years). All participants were right-handed (Edinburgh Inventory, Oldfield, 1971) and native Italian speakers.

\subsection{Materials}

The same set of 120 pairs of sentences described for Experiment 1 was used.

\subsection{Procedure}

Participants were seated in front of a computer screen. The sentences were displayed word-by-word, with each word appearing in the centre of the screen for $300 \mathrm{~ms}$. The inter-stimulus interval was $300 \mathrm{~ms}$, and the inter-trial interval $1500 \mathrm{~ms}$.

The instructions were the same of the reading time experiment, namely participants were asked to read and to understand a series of sentences, some of which could be strange or incorrect. To insure they paid attention during reading, every ten sentences (on average) they had to answer to a question (by pressing a "yes" or a "no" button) about the content of the last sentence. A brief practice session was run to familiarise the participants with the task.

\subsection{Predictions}

As already illustrated in the prediction for the reading time experiment, modular theories predict for syntactic and semantic violations distinct responses and an earlier recognition of the syntactic (number agreement) violation, in that, in a modular model, the syntactic parser immediately and independently computes a syntactic structure that feeds the semantic processor. Instead, interactive theories predict a similar timing for the detection of both violations, given that syntactic and semantic constraints work directly and simultaneously.

In particular, for the distinctiveness of the ERP responses to syntactic and semantic anomalies, we expect for the number-agreement violation a biphasic ERP distribution: a LAN, which should reflect the detection time, followed by a P600, which should reflect the moment of repair. Regarding the consequences of the violations, we expect that the syntactic violations will only produce a temporary disturbance, in that the ease of the diagnosis should produce a quick repair (cf. Fodor et al., 1996). Therefore, after the P600 there should not be any difference between the nonanomalous and syntactically anomalous condition. At the end of the sentence we expect a broad negativity with a centro-parietal distribution. This end-of-sentence negativity has been interpreted as a general sign of difficulty of integration, that has been found in all the cases in which the sentence contains either a syntactic violation (Hagoort et al., 1993; Osterhout \& Mobley, 1995) or a syntactic garden-path (Osterhout \& Holcomb, 1992).

Instead, for the semantic subject-verb agreement violation we expect an N400 widely distributed all over the scalp. The consequences of the semantic violations should extend for a longer time, given that the reader can keep looking for a plausible resolution of the pragmatic odds, and therefore we predict that the N400 for the semantically anomalous condition should be reported on all the words following the critical one until the end of the sentence.

Finally, the earlier detection of the syntactic anomaly as compared to the semantic one, should be reflected in the earlier occurrence of the LAN with respect to the N400.

\subsection{Data acquisition and analysis}

ERPs were recorded from nineteen scalp electrodes placed according to the International 10-20 System (Jasper, 1958) and referred to linked mastoids. Vertical and horizontal eye movements were monitored through 
four electrodes placed around the orbital region (bipolar montage). Electrode impedance was kept below $5 \mathrm{kohm}$ at all scalp and mastoid sites, and below $10 \mathrm{kohm}$ for the eye electrodes.

ERPs and EOG signals were amplified with a SynAmp System (Neuroscan System), with DC-100 Hz bandpass filter, and were digitised continuously with a sampling rate of $500 \mathrm{~Hz}$. The vertical eye movements and blinks were corrected by using VEOG channel as reference, and next data were epoched in the interval $-200 /+3600 \mathrm{~ms}$ with respect to the onset of the target word. Epochs including residual artefacts exceeding 150 $\mu \mathrm{V}$ amplitude were visually inspected and rejected (average percentage of rejection: $35 \%$ of trials which were evenly distributed across the different experimental conditions), and the accepted epochs were averaged.

This rate of rejection, slightly higher than that reported in other ERP studies on language processing, is due to the long epoch which was analysed (the probability to find a large artefact increases linearly with the extent of the analysed epoch) and to the DC recording method adopted that assures the integrity of the slow waves that develop from the target to the terminal word, but this solution increases the frequency of artefacts.

Separate Analyses of Variance (ANOVA) were conducted for the syntactic and semantic condition.

Analyses were focused on the part of the sentence starting from the target word ${ }^{2}$ and going until the final word, in order to have information not only about the critical word, but also about activation evoked by the next words. Therefore, we performed analyses for every word included in this part of the sentence, on mean voltage within 2 time windows following every word onset: $400-500$ and $500-700 \mathrm{~ms}$.

These windows were a priori chosen according to the latency of the classical components elicited by linguistic violations (N400, P600). In each one of these intervals we conducted a 3-way ANOVA with repeated measures on sentence-type (correct vs. incorrect), word position (4 levels for syntactic condition: first word $=$ target, second word, third word, fourth word = final; 5 levels for semantic condition: first word $=$ target, second word, third word, fourth word, fifth word = final) and electrode group (frontal: mean of F3, Fz, F4; central: mean of $\mathrm{C} 3, \mathrm{Cz}, \mathrm{C} 4$; parietal: mean of $\mathrm{P} 3, \mathrm{Pz}, \mathrm{P} 4)$. Further analyses were conducted on the critical word to test the hypothesis that syntactic violation also evokes an early LAN. For this a priori specific hypothesis we used a one-tailed t-test for repeated measures. We measured LAN by comparing syntactic violation with control condition and using the mean amplitude of four electrodes placed over left hemisphere (T3, C3, F3, F7) in the $350-450 \mathrm{~ms}$ time window. A further analysis was

\footnotetext{
${ }^{2}$ ERPs limited to the target word are also analysed in Angrilli et al. (2002).
}

performed in order to establish the precise timing of the two violations. The $300-500 \mathrm{~ms}$ epoch was divided into $10 \mathrm{~ms}$ intervals. For each interval a one-tailed (we expected the violation to elicit a negativity, a LAN or a N400, compared with the correct sentence) $t$ test was computed for the group of electrodes where the effect was maximum. C3 and T3 electrodes were used for the LAN, while Pz and P4 were used for the N400 (for location of maximum N400 amplitude see also Kutas \& Hillyard, 1983; Kutas \& Van Petten, 1994).

\subsection{Results}

Grandaverage waveforms representing $3600 \mathrm{~ms}$ of potentials evoked by the critical and following words, and relative to the syntactic condition, are presented in Fig. 3. Waveforms relative to the semantic condition are presented in Fig. 4.

Sentences with syntactic violation showed, for the target word (Wl), a clear negativity around $400 \mathrm{~ms}$ at the fronto-central locations of the left hemisphere (Fig. 3). The latency and distribution of this component correspond to the LAN. Syntactic errors also elicited a wide positivity, more pronounced over parietal sites, starting about $500 \mathrm{~ms}$ and sustained until $700 \mathrm{~ms}$ after the onset of the critical word. At the level of W3, about $400 \mathrm{~ms}$ after word onset, syntactic anomaly evoked a relative negativity, which was more evident at fronto-central sites (see Fig. 3, Fz electrode). This negativity elicited by the anomalous sentence continued and developed during the 400-700 ms interval after both W3 and W4 onset.

Statistical analyses supported these observations. In the $400-500 \mathrm{~ms}$ time window there was a significant sentence-type by word position interaction $(F[3,72]=$ $2.88, p=.04,(M S E=19.12)$ : The last two words in the incorrect sentence (W3 and W4) evoked a significant greater negativity than the corresponding words in the correct sentence (Newman-Keuls post hoc, $p=.05$ ), whereas in the same interval no difference was found for $\mathrm{W} 1$ and $\mathrm{W} 2$.

In the 500-700 ms time window (which, for the target word, corresponds to the P600 component) there was a significant sentence-type by word position interaction $(F[3,72]=6,5, p=.01,(M S E=60.12)$, with the critical word (Wl) in the incorrect sentence significantly more positive than in the control condition (Newman-Keuls post hoc, $p=.05$ ). Instead, in the same time window, the last two words (W3 and W4) showed a significant negativity for the syntactic anomaly compared with the correct sentence condition (Newman-Keuls post hoc, $p=.05$ ).

Furthers analysis was focused on the target word, in the $350-450 \mathrm{~ms}$ time window, and included the mean amplitude of 4 left anterior electrodes (T3, C3, F3, F7). This statistic tested the presence of the component termed LAN and showed a significant negativity 
$\begin{array}{llllll}\text { F3 Fz } & \text { Fz } & \text { F4 }\end{array}$
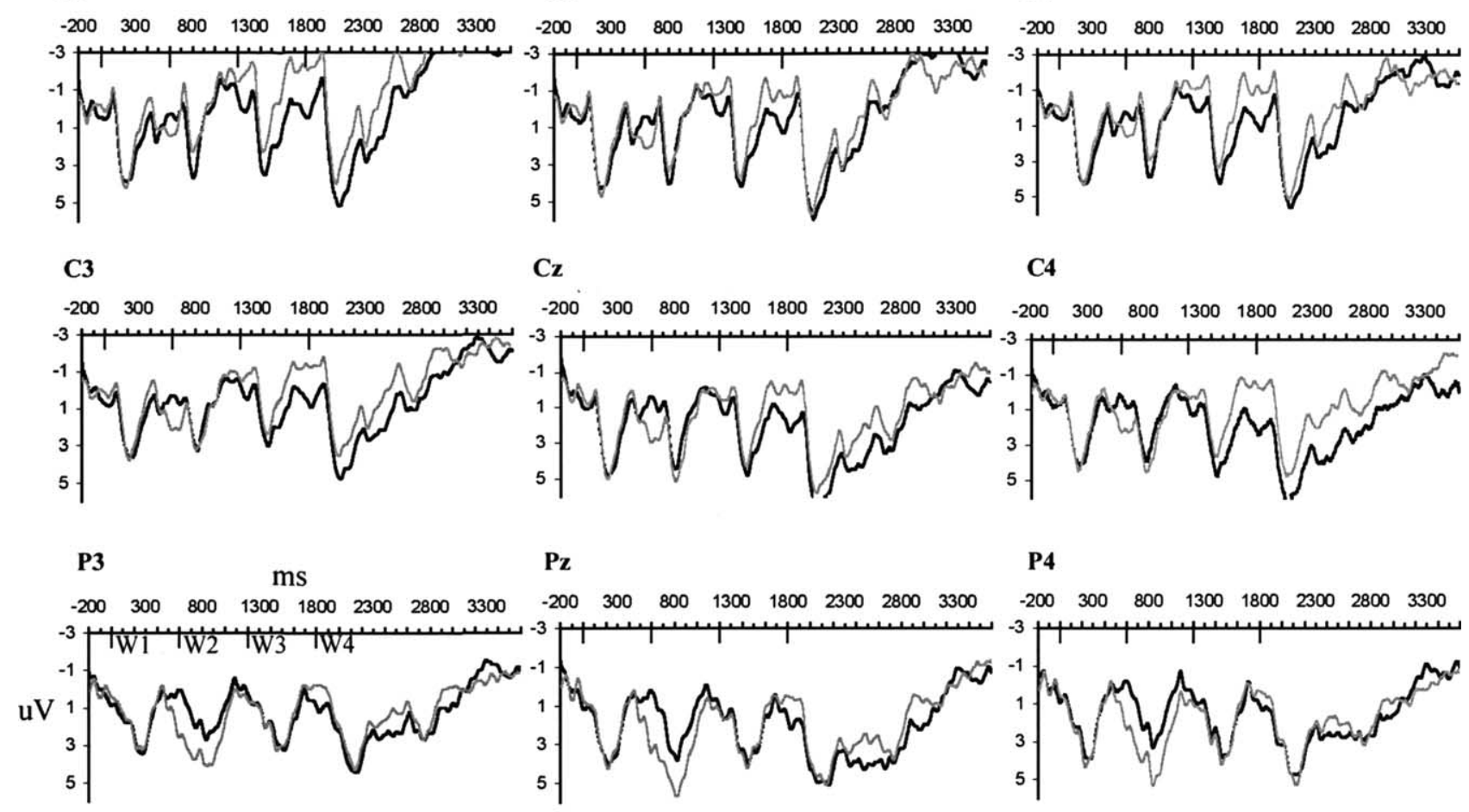

\section{Correct
Incorrect}

Fig. 3. Grand average ERPs recorded over three midline and 6 lateral sites to subject-verb Number agreement violations sentences and controls. Onset of the critical words in non-violating (solid lines) and number agreement violating (dashed lines) conditions is indicated by the vertical bar. Positive voltage is plotted down.

$(t[23]=1.86, p=.04$, one-tailed $t$ test $)$ to syntactic violations as compared with the control condition (see Fig. 3, in particular F3 and C3 around $400 \mathrm{~ms}$ of W1 latency).

The LAN effect was not significant in the $400-500 \mathrm{~ms}$ time-window, nor was it significant in the homologous right electrodes.

The grandaverage waveforms of the semantic condition (Fig. 4) showed for incorrect sentences a negative component that reached the maximum over centro-parietal electrodes at about $450 \mathrm{~ms}$ after the onset of the target word. This negativity evoked by semantic violations did involve all words that followed the target word (Wl), and it was more evident at parietal locations (Fig. 4) while, at frontal sites, it was visible mainly after the third word.

In line with these observations, statistical analyses showed a significant main effect of sentence-type $(F[1,24]=5.49, p=.03, \quad(M S E=121.9)$ for the 400 $500 \mathrm{~ms}$ interval, with the anomalous condition always more negative (that is, for every word till the end of sentence) than the control one. On the contrary, in the 500-700 ms time window there was no effect for any word (from $\mathrm{Wl}$ to W5). In this interval the negativity generated by incongruity was too small to reach significance. These results are consistent with latency and scalp distribution of N400 elicited by semantic incongruity in other languages. Moreover, they support our reading time study and our predictions: Indeed, semantic violations induce a clear negativity starting at target word and extending until the end of the sentence.

Finally, a further analysis was conducted on small $(10 \mathrm{~ms})$ intervals within the $300-500 \mathrm{~ms}$ epoch to measure the onset of the significant effects elicited by the target word (Wl) for the two kinds of violation. The LAN was significant, in $\mathrm{C} 3$ and $\mathrm{T} 3$ locations, starting at $340 \mathrm{~ms}$ till $400 \mathrm{~ms}$ (one-tailed $t_{24}>1.71, p<.05$ ). The N400 was significant, in Pz and P4 locations, starting at $430 \mathrm{~ms}$ till 470 (one-tailed $t_{24}>2.06, p<.05$ ). Thus, the detection of syntactic violation started $90 \mathrm{~ms}$ before the detection of semantic one.

\subsection{Discussion}

The ERPs are congruent with the reading time data in two respects. First of all, syntactic and semantic violations elicit a distinct electrophysiological pattern. Specifically, syntactic anomalies show a biphasic distribution with a LAN followed by a late positive shift (P600) on the critical word, and a sustained negativity 
F3

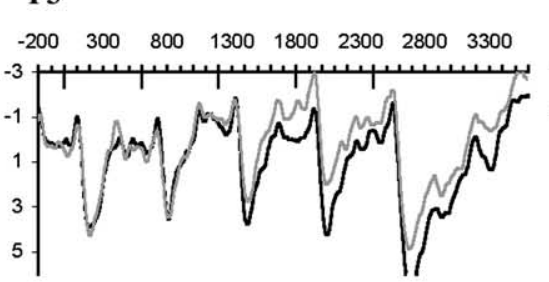

C3

$\begin{array}{llllllll}-200 & 300 & 800 & 1300 & 1800 & 2300 & 2800 & 3300\end{array}$

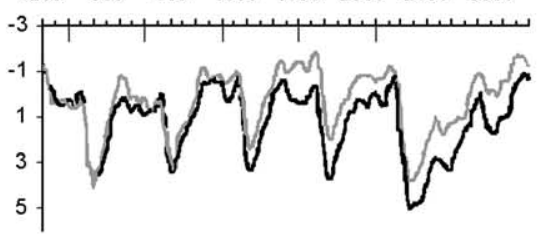

P3

$\begin{array}{llllllll}-200 & 300 & 800 & 1300 & 1800 & 2300 & 2800 & 3300\end{array}$

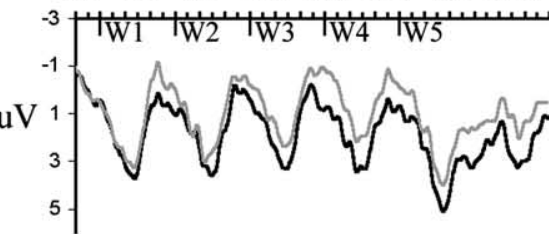

\section{Correct}

$\mathbf{F z}$

$\begin{array}{llllllll}-200 & 300 & 800 & 1300 & 1800 & 2300 & 2800 & 3300\end{array}$

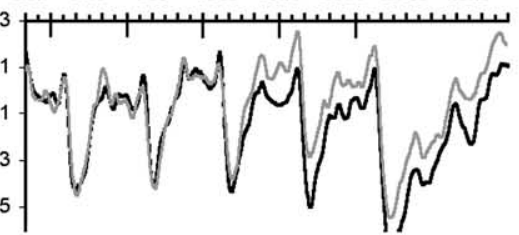

$\mathrm{Cz}$

$\begin{array}{llllllll}-200 & 300 & 800 & 1300 & 1800 & 2300 & 2800 & 3300\end{array}$

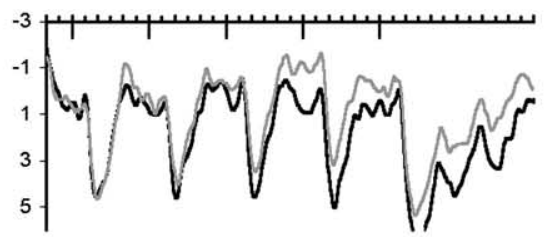

F4

$\begin{array}{llllllll}-200 & 300 & 800 & 1300 & 1800 & 2300 & 2800 & 3300\end{array}$

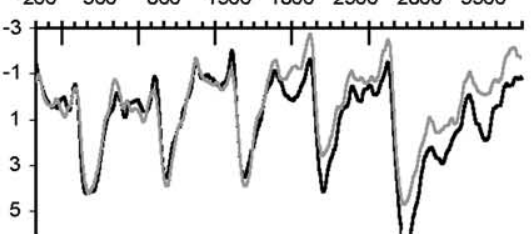

C4

$\begin{array}{llllllll}-200 & 300 & 800 & 1300 & 1800 & 2300 & 2800 & 3300\end{array}$

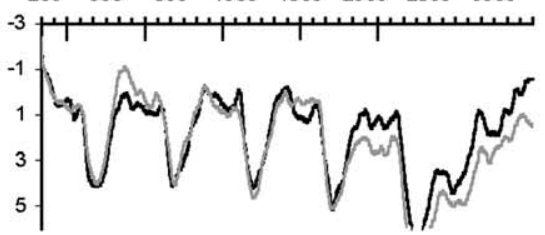

P4
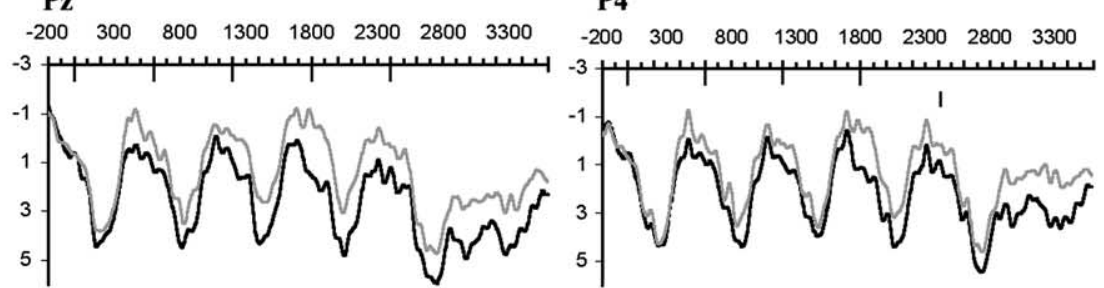

\section{Incorrect}

Fig. 4. Grand average ERPs recorded over three midline and 6 lateral sites to subject-verb Semantic agreement violations sentences and controls. Onset of the critical words in non-violating (solid lines) and number agreement violating (dashed lines) conditions is indicated by the vertical bar. Positive voltage is plotted down.

on the final words. Instead, semantic anomalies elicit a monophasic pattern with a N400 effect lasting until the end of the sentence.

The second respect, regarding the timing of the detection, the LAN elicited by the syntactic anomaly is significant starting at $340 \mathrm{~ms}$ whereas N400 started to become significant only $90 \mathrm{~ms}$ later, at $430 \mathrm{~ms}$ of latency. This distinction in scalp location and detection time to semantic and to syntactic anomalies points to the conclusion that the parser constructs distinct syntactic and semantic analyses of a sentence.

\section{General discussion}

There is converging evidence between behavioural and electrophysiological data on the fact that the number agreement violation is detected earlier than the semantic one. Further, the two violations differ in the sentence time-course: while syntactic violations produce an immediate perturbation that quickly returns to baseline, the effects of the semantic violations last until the end of the sentence.

The ERPs data are consistent with the reading time data. The two types of violations show different patterns: on the critical word syntactic anomalies elicit a biphasic response, a LAN and a P600, while semantic anomalies elicit a N400. Furthermore, the onset of the LAN effect in the syntactic violation condition occurs 90 ms earlier than the N400 effect in the semantic condition. Finally, the consequences of the violation differ in the pattern of word sequence: After the critical word the waveforms elicited by syntactic violations return to baseline and are followed by an end of sentence negativity, while the negative waveforms elicited by semantic violations continues until the end of the sentence.

These distinct patterns to semantic and to syntactic anomalies support the idea that there is an early parsing stage, in which structural information is consulted to construct an initial sentence interpretation, word-byword, on the basis of structural information alone. This is a state of affair envisaged by modular models, as illustrated by Frazier (1987a, 1987b) and Gorrell (1995). These models postulate at least two sub-stages in the syntactic analysis: A first stage where only constituent structural information is used to build a syntactic representation, and a second stage in which structural operations are performed on the already built syntactic tree (cf. also Berwick \& Weinberg, 1984). Subject-verb number agreement is a morpho-syntactic relation assumed to be checked in the second stage of syntactic 
analysis. Specifically, once the tensed verb has been recognised, the parser checks the number features of the verb and of the subject noun and both features should match the subject-verb agreement features. In this second stage, operations of semantic/thematic/pragmatic plausibility evaluation run in parallel with syntactic processes. However, there is an intrinsic seriality among semantic/pragmatic evaluation operations and syntactic operations, in that, for example, the semantic plausibility of a subject/verb relation can only be evaluated when the thematic processor is provided with a relation to be evaluated that is represented in its own vocabulary, for example, as being an external or an internal argument. And this is exactly the work of the syntactic processor (Frazier, 1990).

An interesting question is whether the ERP responses are fine-grained enough to reflect the distinct stages of parsing models that have been proposed on the bases of behavioural data. The answer to the question seems positive and Friederici (2002) has presented a neurocognitive model that is largely compatible with the modular framework. In Friederici's model, the two stages of syntactic analysis are reflected by distinct ERP responses: The first stage (Phase 1) is reflected by the ELAN, that is the early negativity found in response to phrase structure violations. The second stage (Phase 2) is tagged by both the LAN, which reflects morphosyntactic operations, and the N400, which reflects lexical semantic information and thematic role assignment operations. The two processing domains are thus viewed as functionally distinct but not distinguished on temporal parameters.

The computation of a subject-verb number agreement violation as the one used in this study should therefore be reflected within Phase 2, because it pertains to checking morpho-syntactic features. Further, because it is syntactic in nature, it should be distinct from the semantic one both in timing and in scalp distribution. Being in Phase 2, we should therefore expect a LAN, which is exactly what we got. However, our data also show an earlier appearance of the LAN with respect to the N400. This happens despite the fact that the relative timing of the availability of different types of information to the parser goes in the opposite direction: the relevant semantic information is available on the root of the verb while the number information is available on the suffix (i.e., after the semantic information encoded in the verb stem is processed). Therefore, we suggest that the inherent seriality of the syntactic and semantic processes should be also incorporated in Friederici's neuropsychological model. In other words, we propose that checking of the morphosyntactic feature of number between subject and verb should generate an ERP response with an earlier appearance than the semantic integration processes reflected by the N400.

\section{Relationship to other ERP studies}

The N400 effect we found in response to semantic violations in Italian replicates the standard finding on the topic in the literature (see Section 1). The following discussion will therefore, focus on the response to the syntactic violations for which the available literature is less univocal because different types of syntactic violations have been studied.

The present data on subject-verb number agreement violations fit very well with the strictly comparable English study by Osterhout and Mobley (1995). This study used linguistic material of the same type and the same methodology (i.e., the critical word was a verb in sentence internal position) and found the same ERP effects, that is, a LAN and a P600 on the critical word. Kutas and Hillyard (1983) also found a frontal negativity and a late positive wave in response to their sentences violating subject-verb number agreement in English. Although the effects were considered marginal by the authors, given the number of statistical comparisons involved in the study, they are consistent with an interpretation in terms of LAN and P600.

An apparent counter-example to these two ERP studies is one by Hagoort et al. (1993) in Dutch, with a subject-verb number agreement violation in sentence internal position. A P600, but not a LAN, was reported. However, the authors only analysed the 500 $800 \mathrm{~ms}$ time window, and therefore, it is possible that a LAN effect was present in their data, but not analysed. In fact, in a subsequent study with auditory presentation, Hagoort and Brown (2000b), with the same material used by Hagoort et al. (1993), but analysing a more extended time-window, reported both a LAN and a P600.

Finally, Coulson et al. (1998) evaluated the ERPs elicited by subject-verb number agreement violation in English, manipulating also the probability of occurrence of violated sentences. They found both an early negativity and a late positive wave. However, the early negativity exhibited a centro-parietal distribution. This result fits with the proposal advanced by Friederici (personal communication) who argues that morphosyntactic violations, at least under certain circumstances, should elicit an N400 instead of a LAN. This would happen when a thematic role assignment is implausible and the mismatch prevents the building up of a coherent syntactic structure. In other word, we should expect a LAN when the violation is perceived as a functional problem of checking the concordance of syntactic features, while we should expect an N400 when the mismatch is perceived as an interpretational problem of role assignment. The data of Coulson et al. (1998) are consistent with the latter interpretation and suggest that subject-verb number agreement was interpretationally relevant in their experiment. 
We would like to suggest that subject-verb number agreement is primarily a feature that is syntactic in nature: It is a process carried out in the second stage of parsing on the syntactic structure built up in stage one, and thus it should precede, or at least it should be independent from, the integration of semantic/pragmatic information. Why, then, did not the pattern obtained by Coulson at al. with subject-verb violations present a LAN? It is worth noting that the participants in their experiment were aware of the probability manipulation (as reported by the authors). In fact, both the within subject probability of occurrence manipulation and the lack of filler sentences may have introduced a task-orienting bias despite the use of a "reading-only" task. Thus, this condition may have increased the saliency of the violations and may have forced participants to respond to the task requirements by directing their attention on the critical features of the sentences. Thus, it is possible that the experimental conditions biased participants to bypass agreement feature checking on the verb in favour of an immediate "interpretation." In support of this hypothesis there is the result reported by Coulson et al. (1998, p. 44) that the distribution of the negativity for subject-verb agreement was not affected by grammaticality, but by probability. In other words, correct sentences also elicited a negativity at the verb, when "correctness" was improbable in the list.

In summary, apart from data reported by Coulson et al. (1998), our Italian data are in line with the ERPs elicited by the same type of violations in other languages and they provide cross-linguistic evidence for a universal parsing mechanism, where the separability of the processes and the way they interact hold across different languages.

\section{Reading time data and ERP data}

The reading time data proved to be an efficient methodology to study fine grained issues in language processing. In fact, they show effects that are in line with the findings obtained in English with different methodologies (eye-movement patterns and lexical decision) concerning the consequences of the violations (Braze et al., 2002; Fodor et al., 1996; Ni et al., 1998). As for the time of the initial perception of the violation, the present results, both from reading times and ERPs, are in line with data on English reported by Boland (1997), Braze et al. (2002), and McElree and Griffith (1995) but not with those by Fodor et al. (1996) with a lexical decision task. In the latter case syntactic and semantic violations produced simultaneous effects. Note, however, that Fodor and colleagues used a tense violation in their study. This violation may be more complex to compute than a straight number agreement violation, because it involves checking both tense and aspect fea- tures of the auxiliary and of the verb. While the former seems intrinsic to the construction of a phrase structure representation, the second one seems more related to sentence interpretation. Thus, this complexity can bring about a slight delay in the computation of the tense violation, such that, under certain boundary conditions, pragmatic and tense violations show similar detection time.

Some ERP data may be interpreted as supporting this explanation. In a study by Osterhout and Nicol (1999), in which the same material as Fodor et al. (1996) was used, a P600, but not a LAN, was found. In addition, they reported a negativity in the right hemisphere, significant in the 400-500 ms time-window, that is with a slightly later appearance than the classic LAN. The lack of a LAN can be explained by the fact that the tense violation has a longer computation time than a number agreement violation and therefore, it is not computed in the time interval compatible with a LAN latency. Further, as said above, it presumably does not entail the same linguistic processes that produce a LAN.

A last issue we would like to touch upon stems from a comparison of our reading time study and the ERP study with respect to sentence final effects. The reading times show the so called wrap-up effect (Just \& Carpenter, 1980), that is an increase in reading time on the last word that affects all sentences, with or without violations (cf. Figs. 1 and 2). The causes of the wrap-up effects have never been fully identified (cf. Frazier, 1999). Generally, they include all the processes of semantic interpretation of the sentence in a broad sense, such as establishing its true-value properties, establishing the referents of free pronouns, integrating the sentence into a discourse, establishing the speech act of the sentences (i.e., if it is a question or an assertion). The reading times show that, on top of the wrap-up effect, semantic violations have a longer reading time than baseline. This is not the case for the syntactic violation. This seems to indicate that the perturbation produced by the number agreement error does not have a strong effect at sentence ending. This state of affairs is exactly the same found in the eye movement studies by Braze et al. (2002), Fodor et al. (1996), and Ni et al. (1998): On the last words of the sentence there was an increase in regressions for all the anomaly conditions, but only pragmatic anomaly triggers an increase in excess of the general effect. However, the present ERP study, and in general all those ERP studies in which the syntactic violation is not the last word of the sentence, show an end-of-sentence negativity, that is they show that the final act of sentence interpretation is somehow disturbed by the presence of a syntactic mistake. In this latter respect, therefore, ERPs seem more sensitive to difficulties of sentence interpretation than the other two methodologies. Future research to spell out different aspects of sentence final 
interpretation, through the examination of the consequences of different linguistic anomalies, is certainly needed (see Hagoort et al., 1993, for an effort in this direction).

In summary, we reported data that are congruent with a model of sentence processing that makes a principled distinction between syntactic and semantic processes. The behavioural as well as the ERP data have shown that (a) syntactic violations are detected earlier than semantic violations, (b) the perturbations brought about by syntactic violations are short-lived with respect to those brought about by semantic violations (c) the two types of violations produce ERPs responses that are spatially as well as temporally distinct. Furthermore, the comparison of the present Italian data with similar behavioural and neuro-physiological data obtained in other languages, such as English and Dutch, shows a remarkably similar pattern, pointing out to the universality of the processing mechanisms involved and of the architecture of the language processor.

Finally, regarding more methodological issues, the comparison of reading time and ERP measures shows that both are finely tuned to timing and qualitative distinctions of processing effects. The advantage of the ERP measures, compared also to eye-movements studies, is a better sensitivity to end-of-sentence effects. While this finding requires further investigation, it certainly calls for the methodological need for ERP studies to use linguistic materials where the word bearing the critical linguistic manipulation be kept separate from the last word of the sentence. In fact exactly the ERP sensitivity to end-of sentence effects can be a contamination for critical word effects, when both variables are embodied in the same item.

\section{Acknowledgments}

We would like to thank Colin Brown for initial support in starting an ERP project; Angela Friederici and Lee Osterhout for several comments and scientific consulting all along this ERP enterprise. A special thank to Chuck Clifton for a careful reading of our paper. Portions of this data were presented at 14th Annual CUNY Conference on Human Sentence Processing, 2001, Philadelphia, and at The Neurological Basis of Language: An Interdisciplinary Conference on Aphasiological, Computational, and Neuroimaging Approaches, 2001, Gröningen.

\section{Appendix A}

All experimental sentences are listed below. The critical words are underlined: the first verb is the correct version, the second is the violated one. An English translation is given in parenthesis. However, due to differences between the languages, the English translation often does not contain the same number of words or the same word-order as the Italian material.

\section{A.1. Subject-verb number agreement violation condition}

1. Il cameriere anziano serve/servono con espressione distratta (The old waiter serves/serve with-a vacant look)

2. La segretaria bionda chiama/chiamano per un appuntamento (The blond secretary calls/call for an appointment)

3. La cuoca esperta frigge/friggono nella vecchia cucina (The skilled cook fries/fry in-the old kitchen)

4. La bambina malata gioca/giocano con la bambola (The ill child plays/play with the doll)

5. Il gruppo musicale suona/suonano con grande entusiasmo (The musical group plays / play with great enthusiasm)

6. Il pescatore stanco riposa/riposano vicino al timone (The tired fisherman rests/rest next to-the helm)

7. Il ragazzo straniero legge/leggono sul treno affollato (The foreign boy reads/read in-the crowded train)

8. Il giovane falegname sega/segano senza alcuna fatica (The young carpenter saws/saw without any toil)

9. Il vecchio calzolaio lavora/lavorano con grande perizia (The old shoemaker works/work with great skill)

10. Il medico chirurgo arriva/arrivano appena in tempo (The surgeon arrives/arrive just in time)

11. Le maestre felici parlano/parla a voce alta (The happy teachers speak/speaks in-a loud voice)

12. I macellai esperti tagliano/taglia con grande abilità (The skilled butchers cut/cuts with great ability)

13. I cassieri nervosi contano/conta con estrema cautela (The nervous cashiers count/counts with extreme caution)

14. I postini veloci lavorano/lavora girando in bicicletta (The rapid postmen work/works going-round by bicycle)

15. I nostri vicini potano/pota con le cesoie (Our neighbors trim/trims with the shears)

16. I commessi attenti puliscono/pulisce preparando i saldi (The careful salesclerks clean/cleans preparing the sales)

17. Le mamme econome comprano/compra solo al supermercato (The thrifty mothers buy/buys only atthe supermarket)

18. I nuovi imbianchini stuccano/stucca in modo impreciso (The new painters plaster/plasters in-a careless way)

19. I ragionieri stressati discutono/discute controllando le fatture (The stressed accountants debate/debates checking the invoices) 
20. I pensionati vigorosi leggono/legge senza gli occhiali (The vigorous pensioners $\mathrm{read} / \mathrm{reads}$ without their glasses)

21. Il cane abbandonato abbaia/abbaiano alla luna piena (The abandoned dog barks/bark at-the full moon)

22. La rondine instancabile vola/volano fino a sera (The tireless swallow flies/fly up to-the evening)

23. Il gatto persiano corre/corrono sotto il tavolo (The Persian cat runs/run under the table)

24. La leonessa solitaria vaga/vagano nella notte buia (The lonely lioness roams/roam in-the dark night)

25. La lucertola pigra riposa/riposano al sole tiepido (The lazy lizard rests/rest in-the tepid sun)

26. La gallina bianca cova/covano nel mio fienile (The white hen broods/brood in my hayloft)

27. Il cavallo affaticato dorme/dormono nella sua stalla (The tired horse sleeps/sleep in its stable)

28. Lo squalo grigio nuota/nuotano intorno allo scoglio (The gray shark swims/swim around the rock-cliff)

29. Il coccodrillo affamato sonnec $\mathrm{chia} /$ sonnecchiano vicino al fiume (The hungry crocodile dozes/doze next to-the river)

30. La mucca magra rumina/ruminano sul prato fiorito (The slim cow ruminates/ruminate on-the grass inflower)

31. I canarini gialli beccano/becca senza alcuna sosta (The yellow canaries peck/pecks without a break)

32. Le zebre paurose fuggono/fugge davanti al leopardo (The fearful zebras escape/escapes in-front of-the leopard)

33. I criceti agitati corrono/corre tra le siepi (The excited hamsters run/runs through the hedges)

34. Le lumache lente rientrano/rientra nel loro guscio (The slow slugs come/comes-back in their shell)

35. Le farfalle colorate volano/vola sui fiori gialli (The colored butterflies fly/flies on-the yellow flowers)

36. I ghepardi assetati corrono/corre nella calda savana (The thirsty cheetahs run/runs in-the hot savanna)

37. Le piccole api ronzano/ronza nella calura estiva (The little bees buzz/buzzes in-the summer heat)

38. Le rane rumorose gracidano/gracida nello stagno salmastro (The noisy frogs croak/croaks in-the salt pond)

39. I passeri tranquilli dormono/dorme nel piccolo nido (The calm sparrows sleep/sleeps in-the small nest)

40. Le brune cicale cantano/canta tutta la notte (The brown cicadas sing/sings the whole night)

41. Il treno espresso parte/partono in perfetto orario (The express train leaves/leave on perfect time)

42. Il gelsomino fiorito profuma/profumano nella notte calda (The blossoming jasmine scents/scent in-the warm night)

43. Il ceppo odoroso crepita/crepitano nel nuovo caminetto (The fragrant stump crackles/crackle in-the new fireplace)
44. La macchina sportiva viaggia/viaggiano sulla strada montana (The sporting car travels/travel in-the mountain road)

45. Il faro lontano appare/appaiono nella fitta nebbia (The far lighthouse appears/appear in-the thick fog)

46. La palla rossa rotola/rotolano tra la folia (The red ball rolls/roll into the crowd)

47. La telefonata inattesa arriva/arrivano dagli Stati Uniti (The unexpected phone-call comes/come from-the United States)

48. Il vetro blindato protegge/proteggono dal rumore esterno (The bulletproof glass protects/protect from-the external noise)

49. Il libro si bagna/bagnano sotto la pioggia (The book[self] wets/wet under the rain)

50. Lo scaffale polveroso crolla/crollano per il peso (The dusty shelf collapses/collapse for the weight)

51. I violenti temporali scoppiano/scoppia senza alcun preavviso (The violent storms break/breaks without any warning)

52. Le nuvole nere aumentano/aumenta prima della tempesta (The black clouds increase/increases before the storm)

53. I letti antichi cigolano/cigola in modo fastidioso (The ancient beds squeak/squeaks in-an annoying way)

54. Le stelle lontane brillano/brilla nel cielo terso (The distant stars shine/shines in-the clear sky)

55. Gli arrosti saporiti cuociono/cuoce nella vecchia cucina (The tasty roasts cook/cooks in-the old kitchen)

56. I ciclamini bianchi profumano/profuma in modo delicato (The white cyclamens scent/scents in-a delicate way)

57. I venti estivi soffiano/soffia con intensità crescente (The summer winds blow/blows with increasing intensity)

58. Gli orecchini argentati restano/resta nel cassette chiuso (The silvered earrings stay/stays in-the closed drawer)

59. Le nespole aspre maturano/matura nella paglia asciutta (The sour medlars ripen/ripens in-the dry straw)

60. I muri sbrecciati crollano/crolla poco per volta (The crumbled walls collapse/collapses a-bit at-a time)

\section{A.2. Subject-verb semantic violation condition}

1. La bambina spaventata fugge/piove veloce davanti al cacciatore (The fearful baby escapes/rains quickly in-front of-the hunter)

2. Gli alunni svogliati ascoltano/franano sempre con aria annoiata (The lazy students always hear/slip in-a bored manner)

3. Il bambino biondo mangia/squilla seduto alia nostra tavola (The blond child eats/rings sitting at our table) 
4. La sarta distratta stira/ringhia senza prestare alcuna attenzione (The inattentive tailor irons/growls without paying any attention)

5. L'imputato del delitto confessa/muggisce di fronte al testimone (The accused of the crime confesses/lows in front of-the witness)

6. Lo spettatore straniero applaude/abbaia mostrando un grande entusiasmo (The foreign spectator applauses/barks showing a great enthusiasm)

7. Il piccolo scolaro scrive/tuona lentamente alla lavagna luminosa (The young pupil slowly writes/ thunders at-the overhead projector)

8. La giovane infermiera cura/grandina in modo troppo timoroso (The young nurse treats/hails in-a too timorous way)

9. Il nuovo capotreno fischia/germoglia alla partenza della locomotiva (The new guard whistles/sprouts at-the departure of-the locomotive)

10. L'autista del taxi sterza/evapora per evitare 1'ostacolo improvviso (The driver of-the taxi swerves/evaporates to avoid the unexpected obstacle)

11. Il giocatore incerto esita/marcisce davanti al suo avversario (The uncertain player hesitates/rots infront of his opponent)

12. Il pasticcere esperto guarnisce/nitrisce con la frutta candita (The skilled confectioner garnishes/neighs with the candied fruit)

13. I soldati coraggiosi partono/cigolano al galoppo senza paura (The brave soldiers leave/squeak at-a gallop without fear)

14. Il vecchio pagliaccio inciampa/nevica nelle grosse scarpe rotte (The old clown trips/snows in-the big broken shoes)

15. Il barbone disperato piange/decolla in una via cittadina (The desperate tramp cries/takes off in a city street)

16. Il contadino stanco semina/abbaia senza avere alcuna fretta (The tired farmer sows/barks without being in-a hurry)

17. Il ladro esperto penetra/miagola nella splendida casa vuota (The skilled thief enters/meows in-the splendid empty house)

18. L'insegnante di-inglese spiega/fiorisce nella nuova scuola media (The English teacher explains/flowers in-the new secondary school)

19. Il maggiordomo indiano spolvera/cinguetta nella bella villa moderna (The Indian butler dusts/twitters in-the beautiful modern villa)

20. La campionessa olimpionica nuota/piove nella grande piscina comunale (The Olympic champion swims/rains in-the great town swimmingpool)

21. Il topolino grigio entra/mente nella sua tana segreta (The gray young-mouse enters/lies in its secret den)
22. Le cinque galline covano/parlano nel calore del pollaio (The five hens brood/speak in-the heat of-the henhouse)

23. La mucca pezzata rumina/legge nel grande campo coltivato (The dappled cow ruminates/reads in-the big cultivated field)

24. Il cavallo bianco giunge/ricama primo al prestigioso traguardo (The white horse arrives/embroiders first at-the prestigious finishing-line)

25. La pesante foca sguazza/compra nel mare in tempesta (The heavy seal splashes/buys in the stormy sea)

26. Il possente ippopotamo sbadiglia/scrive nello zoo quasi deserto (The mighty hippopotamus yawns/ writes in-the almost desert zoo)

27. Il merlo nero saltella/dipinge sotto gli alberi fioriti (The blackbird jumps/paints under the blossoming trees)

28. Il vecchio cervo gira/canta sicuro nel fitto bosco (The old deer wanders/sings calmly in-the thick wood)

29. La gazza ladra svolazza/applaude intorno alla casa abbandonata (The thievish magpie flies/claps around the abandoned house)

30. La veloce gazzella fugge/ride di fronte ai predatori (The quick gazelle escapes/laughs in front of-the predators)

31. Il giovane elefante avanza/cucina in modo troppo deciso (The young elephant advances/cooks in-a too resolute way)

32. Il piccolo cane abbaia/racconta festosamente al padrone stanco (The small dog barks/tells warmly tothe tired master)

33. Il giovane gallo canta/giura nel pollaio al mattino (The young cock sings/swears in-the henhouse during-the morning)

34. Il gatto Siamese osserva/scrive con gli occhi socchiusi (The Siamese cat observes/writes with [the] halfopen eyes)

35. Il serpente velenoso dorme/piange nella gabbia di cristallo (The poisonous snake sleeps/cries in-the cage of crystal)

36. Il pappagallo colorato riposa/telefona sul piccolo trespolo metallico (The colored parrot rests/phones on-the small metal perch)

37. Il pesciolino si nutre/vanta con uno strano mangime (The small-fish [self] feeds/boasts with a strange food)

38. Il gambero si muove/spazzola con una lentezza estrema (The prawn [self] stirs/brushes with an extreme slowness)

39. Il gabbiano si posa/ubriaca nei pressi della laguna (The gull [self] alights/gets-drunk near the lagoon)

40. Il morbido pulcino zampetta/declama nella scatola di cartone (The soft chick scampers/declaims inthe box of cardboard) 
41. La pianta esotica fiorisce/recita molto prima del solito (The exotic plant flowers/plays really earlier than usual)

42. La vecchia barca naviga/bacia in porto a mezzanotte (The old boat sails/kisses in-the port at midnight)

43. La lampada fluorescente illumina/dimentica senza dare alcun calore (The fluorescent lamp lights/forgets without giving any warmth)

44. L'olio extra vergine condisce/tossisce in modo molto saporito (The virgin olive-oil dresses/coughs in-a very tasty way)

45. Un mantello pesante scalda/canta nelle notti piu fredde (A heavy cloak warms/sings in-the coldest nights)

46. Il tartufo nero profuma/ascolta in modo molto intenso (The black truffle smells/hears in-a very intense way)

47. I bicchieri antichi vibrano/ridono per il gran rumore (The ancient glasses resound/laugh for the loud noise)

48. La penna stilografica cade/fuma dal vecchio tavolo inclinato (The fountain pen falls/smokes from-the old tilted table)

49. La valanga si ferma/pente contro un muro resistente (The avalanche [self] stops/regrets against a resistant wall)

50. La terra si spacca/appende sotto il solleone estivo (The ground [self] breaks/hangs under the summer heat)

51. La cassettiera antica cede/corre a causa dei tarli (The ancient chest-of-drawers caves-in/runs because of the woodworms)

52. Il fiume stagionale sfocia/ride spesso in modo impetuoso (The seasonal river often flows/laughs in impetuous way)

53. Il bocciolo si apre/tuffa sulla pianta di rosa (The bud [self] opens/dives on-the plant of rose)

54. Chicchi di grandine scendono/cucinano da un cielo cupo (Grains of hail descend/cook from a dark sky)

55. La torre medievale resiste/studia nonostante il violento terremoto (The medieval tower stands up/ studies despite the violent earthquake)

56. Il vecchio disco fruscia/spera gia da molto tempo (The old record rustles/hopes already from a long time)

57. La voce umana cambia/nuota nel corso degli anni (The human voice changes/swims as years go by)

58. La roccia si sgretola/pettina col taglio degli alberi (The rock [self] crumbles/combs because-of-the cutting of-the trees)

59. L'incendio nel villaggio divampa/recita violento in un attimo (The fire in-the village blazes/plays violently in a moment)

60. La campana bronzea invita/giura alla messa della domenica (The bronzy bell invites/swears to the Sunday mass)

\section{References}

Ainsworth-Darnell, K., Shulman, H. G., \& Boland, J. E. (1998). Dissociating brain responses to syntactic and semantic anomalies: Evidence from event-related potentials. Journal of Memory and Language, 38, 112-130.

Angrilli, A., Penolazzi, B., Vespignani, F., De Vincenzi, M., Job, R., \& Ciccarelli, L. (2002). Cortical brain responses to semantic incongruity and syntactic violation in Italian language: An EventRelated Potential study. Neuroscience Letters, 322, 5-8.

Bates, E., \& MacWhinney, B. (1987). Competition, variation, and language learning. In B. MacWhinney (Ed.), Mechanisms of language acquisition. Howe: Lawrence Erlbaum Associates.

Berwick, R., \& Weinberg, A. (1984). The grammatical basis of linguistic performance. Cambridge, MA: MIT Press.

Boland, J. E. (1997). The relationship between syntactic and semantic processes in sentence comprehension. Language and Cognitive Processes, 12, 423-484.

Braze, D., Shankweiler, D., Weijia Ni, \& Palumbo, L. C. (2002). Readers' eye movements distinguish anomalies of form and content. Journal of Psycholinguistic Research, 31, 25-44.

Coulson, S., King, J., \& Kutas, M. (1998). Expect the unexpected: Event-related brain response to morphosyntactic violations. Language and Cognitive Processes., 13, 21-58.

De Vincenzi, M. (1991). Syntactic parsing strategies in Italian. Holland: Dordrecht, Kluwer Academic Publishers.

Fodor, J. A. (1983). Modularity of mind. Cambridge, MA: MIT Press.

Fodor, J. D., Ni, W., Crain, S., \& Shankweiler, D. (1996). Tasks and timing in the perception of linguistic anomaly. Journal of Psycholinguistic Research, 25, 25-57.

Forster, K. I. (1979). Levels of processing and the structure of the language processor. In W. E. Cooper, \& E. C. T. Walker (Eds.), Sentence processing. Hillsdale, NJ: Erlbaum Press.

Frazier, L. (1987a). Sentence Processing: A tutorial review. In M. Coltheart (Ed.), Attention and performance XII. Hillsdale, NJ: Erlbaum Press.

Frazier, L. (1987b). Theories of Sentence Processing. In J. Garfield (Ed.), Modularity in knowledge representation and natural language processing. Cambridge, MA: MIT Press.

Frazier, L. (1990). Exploring the architecture of the language processing system. In G. T. M. Altmannn (Ed.), Cognitive models of speech processing: Psycholinguistics and computational perspectives. Cambridge, MA: MIT Press.

Frazier, L. (1999). On sentence interpretation. Dordrecht, Holland: Kluwer Academic Publishers.

Frazier, L., \& Fodor, J. D. (1978). The sausage machine: A new twostage parsing model. Cognition, 6, 291-326.

Frazier, L., \& Rayner, K. (1982). Making and correcting errors during sentence comprehension: Eye movements in the analysis of structurally ambiguous sentences. Cognitive Psychology., 14, 178210.

Freedman, S. E., \& Forster, K. I. (1985). The psychological status of overgenerated sentences. Cognition, 19, 101-132.

Friederici, A. D. (2002). Towards a neural basis of auditory sentence processing. Trends in Cognitive Sciences, 6, 78-84.

Friederici, A. D., \& Mecklinger, A. (1996). Syntactic parsing as revealed by brain responses: First-pass and second pass parsing processes. Journal of Psycholinguistic Research., 25, 157-176.

Friederici, A., Pfeifer, E., \& Hahne, A. (1993). Event-related brain potentials during natural speech processing: Effects of semantic, morphological and syntactic violations. Cognitive Brain Research, $1,183-192$

Gorrell, P. (1995). Syntax and parsing. Cambridge, England: Cambridge University Press

Gunter, T. C., Stowe, L. A., \& Mulder, G. (1997). When syntax meets semantics. Psychophysiology, 34, 660-676. 
Hagoort, P., \& Brown, C. (2000a). ERP effects of listening to speech: Semantic ERP effects. Neuropsychologia, 38, 1518-1530.

Hagoort, P., \& Brown, C. (2000b). ERP effects of listening to speech compared to reading: The P600/SPS to syntactic violations in spoken sentence and rapid serial visual presentation. Neuropsvchologia., 38, 1531-1549.

Hagoort, P., Brown, C., \& Groothusen, J. (1993). The syntactic positive shift (SPS) as an ERP measure of syntactic processing. Language and Cognitive Processes., 8, 439-483.

Istituto di Linguistica Computazionale del CNR, 1989 Corpus di Barcellona. Pisa: ILC.

Jasper, H. H. (1958). The ten-twenty electrode system of the international federation, electroencephalography and clinical. $\mathrm{Neu}$ rophysiology, 10, 371-375.

Just, M. A., \& Carpenter, P. (1980). A theory of reading: From eye fixations to comprehension. Psychological Review, 85, 109-130.

Kaan, E., Harris, A., Gibson, E., \& Holcomb, P. (2000). The P600 as an index of syntactic integration difficulty. Language and Cognitive Processes, 15, 159-201.

Kutas, M., \& Hillyard, S. A. (1983). Event-related brain potentials to grammatical errors and semantic anomalies. Memory and Cognition, 11, 539-550.

Kutas, M., \& Van Petten, C. (1994). Psycholinguistics electrified: Event-related brain potential investigations. In M. A. Gernsbacher (Ed.), Handbook of psycholinguistics (pp. 83-143). San Diego: Academic Press.

MacDonald, M. C., Pearlmutter, N. J., \& Seidenberg, M. S. (1994). The lexical nature of syntactic ambiguity resolution. Psychological Review, 101, 676-703.

MacWhinney, B., \& Bates, E. (1989). The cross-linguistic study of sentence processing. Cambridge, UK: Cambridge University Press.

Marslen-Wilson, W. D. (1975). Sentence perception as an interactive parallel process. Science, 189, 226-228.

McElree, B., \& Griffith, T. (1995). Syntactic and thematic processing in sentence comprehension: Evidence for a temporal dissociation. Journal of Experimental Psychology: Learning, Memory, and Cognition, 21, 134-157.

McKinnon, R., \& Osterhout, L. (1996). Constraints on movement phenomena in sentence processing: Evidence from event-related potentials. Language and Cognitive Processes., 11, 495-523.
Neville, H. J., Mills, D. L., \& Lawson, D. L. (1992). Fractionating language: Different neural subsystems with different sensitive periods. Cerebral Cortex, 2, 244-258.

Neville, H. J., Nicol, J. L., Barss, A., Forster, K. I., \& Garrett, M. F. (1991). Syntactically based sentence processing classes: Evidence from event-related brain potentials. Journal of Cognitive Neuroscience, 3, 151-165.

Ni, W., Fodor, J. D., Grain, S., \& Shankweiler, D. (1998). Anomaly detection: Eye movement patterns. Journal of Psycholinguistic Research, 27, 515-539.

Oldfield, R. C. (1971). The assessment and analysis of handedness: The Edinburgh Inventory. Neuropsychologia, 9, 97-113.

Osterhout, L., \& Holcomb, P. J. (1992). Event-related brain potentials elicited by syntactic anomaly. Journal of Memory and Language, 31, 785-806.

Osterhout, L., \& Holcomb, P. J. (1993). Event-related brain potentials and syntactic anomaly: Evidence of anomaly detection during the perception of continuous speech. Language and Cognitive Processes, 8, 413-438.

Osterhout, L., \& Holcomb, P. J. (1995). Event-related potentials and language comprehension. In M. Rugg, \& M. G. H. Coles (Eds.), Electrophysiology of mind (pp. 171-215). Oxford: Oxford University Press.

Osterhout, L., \& Mobley, L. A. (1995). Event-related brain potentials elicited by failure to agree. Journal of Memory and Language, 34, 739-773.

Osterhout, L., \& Nicol, J. (1999). On the distinctiveness, independence, and time course of the brain responses to syntactic and semantic anomalies. Language and Cognitive Processes, 14, 283-317.

Penke, M., Weyerts, H., Gross, M., Zander, E., Münte, T. F., \& Clahsen, H. (1997). How the brain processes complex words: An event-related potentials study of German verb inflection. Cognitive Brain Research, 6, 37-52.

Rosier, F., Putz, P., Friederici, A., \& Hahne, A. (1993). Event-related brain potentials while encountering semantic and syntactic constraint violations. Journal of Cognitive Neuroscience, 5, 345-362.

Taraban, R., \& McClelland, J. R. (1988). Constituent attachment and thematic role assignment in sentence processing: Influences of content-based expectations. Journal of Memory and Language, 27, 597-632. 